\title{
Can an ethical question answered with a "Yes, but..." ever be defensible?
}

SADJ March 2020, Vol. 75 No. 2 p 101 - p103

LM Sykes ${ }^{1}$, E Crafford ${ }^{2}$, C Bradfield ${ }^{2}$

\section{INTRODUCTION}

This paper will use the issue of sterility of medical equipment as an example, but the points discussed may be extrapolated to a number of other areas in the dental setting.

In 1970 Spaulding suggested that all medical equipment and instruments be grouped into one of three categories according to the risk of infection during their use. $\mathrm{He}$ then suggested that they be cleaned and treated accordingly by either "sterilization" or "high-level disinfection" where sterilization refers to "a procedure that inactivates all microorganisms, including resistant bacterial spores, resulting in a device that is free of all living microorganisms", and high-level disinfection as "a procedure that inactivates all fungi, viruses, and vegetative microorganisms, but not all bacterial spores". ${ }^{1}$ The three categories and protocols to follow are:

\section{Critical equipment}

Devices that enter sterile tissues, including the vascular system and which should be cleaned and sterilized between use.

\section{Semicritical equipment}

Devices that come into contact with non-intact skin or mucous membranes but do not penetrate them, and should be cleaned and followed by high-level disinfection as a minimum, but preferably sterilized between use.

\section{Noncritical equipment}

Devices that touch intact skin and not mucous membranes, or do not directly touch the patient. These should be cleaned and preferably also treated with low-level disinfection.

\section{Author affiliations:}

1. Leanne M Sykes: BSc, BDS, MDent, IRENSA, Dip Forensic Path, Dip ESMEA, Head of Department of Prosthodontics, University of Pretoria, South Africa.

ORCID Number: 0000-0002-2002-6238

2. Elmine Crafford: $B C h D, B C h D$ Hons, Oral Medicine, MChD OMP Senior Specialist Department of Oral Medicine and Periodontics, University of Pretoria, South Africa.

3. Charles Bradfield: B Tech, BChD, Dip Aesthetics, Registrar Department of Prosthodontics, University of Pretoria, South Africa.

Corresponding author: Leanne M Sykes

Head of Department of Prosthodontics,

University of Pretoria, South Africa.

Email: leanne.sykes@up.ac.za

Author contributions:

1. Leanne M Sykes: Primary author $-40 \%$

2. Elmine Crafford: Secondary author $-30 \%$

3. Charles Bradfield: Registrar - $30 \%$

\section{ACRONYM}

CDC: Centers for Disease Control

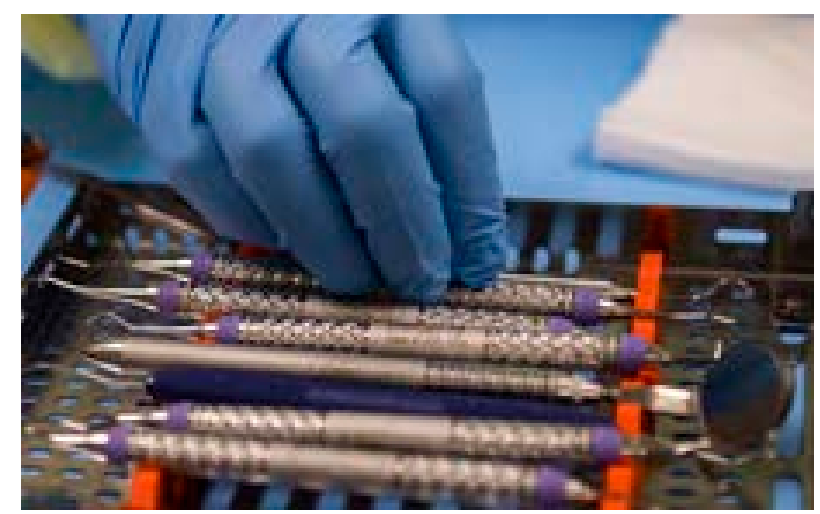

Image source: by Senior Airman Janiqua P. Robinson (U.S. Air Force photo).

This protocol is logical, simplistic and effective if used correctly. However many studies have revealed that there are still often large gaps between what is recommended and what is practiced clinically. ${ }^{2}$

Rutala et al. reported on a study where over $50 \%$ of medical institutions were correctly cleaning and disinfecting their equipment, but then rinsing them with tap water after processing, and thereby re-exposing them to a variety of waterborne organisms. ${ }^{3}$

In addition, the CDC Guidelines for environmental control is constantly updating its policies as newer, more effective chemical agents become available, or the efficacy of older regimes deteriorates. ${ }^{4}$ The onus is thus on clinicians to be aware of and use the latest recommended regimes for each class of equipment or instruments.

The necessary information is readily available on internet sites, which makes it unacceptable to try to justify oversights in sterility by pleading unintentional ignorance or adherence to outdated practices. It goes without saying that it is totally indefensible if they are as a result of blatant disregard or neglect.

A complacent attitude and drop in levels of infection control may also develop over time, especially if no serious consequences are ever noticed. It is expected that every effort must be made by a reasonable healthcare practitioner to obtain and understand the latest protocols and best practice in this regard. 


\section{ETHICAL SCENARIO}

A patient's risk of becoming infected from unsterile instruments will depend on a number of factors. These include the procedure being carried out, the type of organisms present, their transferability, infectivity and pathogenicity, as well as the patient's state of immunity.

No clinician can know which of these factors may be at play in any given situation. As such they should always expect, plan and behave according to protocols for the worst risk situation in terms of microorganism pathogenicity, transfer and patient immunity.

This entails strict adherence to the recommended sterilization and disinfection guidelines for all instruments as well as during all stages of clinical treatment. This will also help safeguard theirs and their staff's health and safety.

The above mentioned guidelines are non-negotiable in any reputable dental practice. Furthermore, time constraints and financial justification can never be used as factors to mitigate against following the correct procedures.

The ethical issues to consider will arise when a clinician finds themselves in a less-than-ideal setting, with a limited supply of instruments, insufficient disinfecting agents or inferior sterilizing facilities. This is often the case in rural South African settings, made worse by high volumes of patients seeking treatment. Is it then permissible to treat with instruments that may have only been washed, perhaps disinfected but probably not fully sterilized?

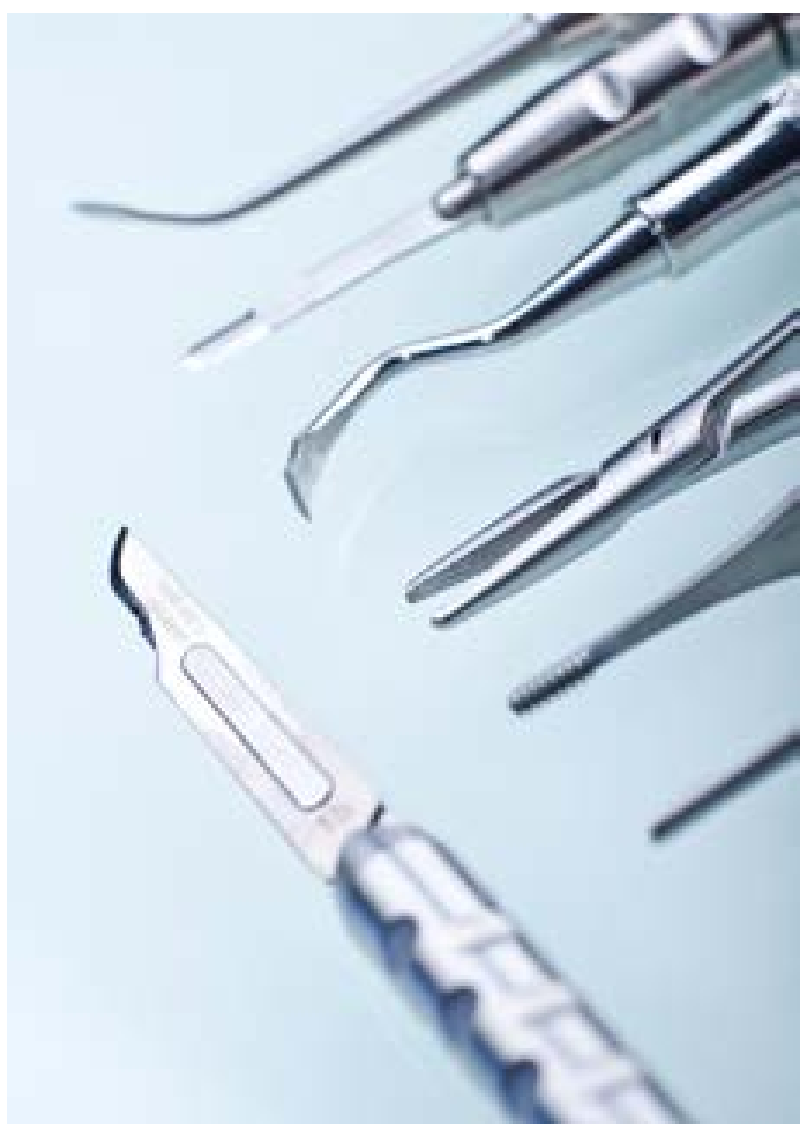

\section{DISCUSSION POINTS}

Can and should the dentist go ahead and treat the patients with potentially hazardous equipment? We may debate this question in terms of the four-principles approach to ethics as developed by Beauchamp and Childress in $1983 .{ }^{5}$ These are:

\section{Beneficence (doing good)}

\section{Non-maleficence (do no harm)}

\section{Respect for patient autonomy}

\section{Justice}

When considering beneficence and non-maleficence, the clinician may wish to do good and help the patients, but at the same time feel compelled to refuse treatment because of concerns that the working conditions are not ideal, and the possible harms this may cause.

This will result in them turning away a number of patients who could be in pain, or suffering from serious dental infections. What then will happen to these patients? They may have traveled long distances, taken time off work, spent their hard earned money getting to the clinic, and have no other means of getting treatment. They may develop exacerbated pain or more serious complications and could resort to seeking help from some other, perhaps untrained or even risky and dangerous persons.

If the dentist debates the issue using the principle of respect for autonomy, they may decide to advise the patient about all the limitations and potential problems involved in treatment, and allow them to decide for themselves if they are prepared to take the risk? They could then ask the patient to sign consent for treatment and cover themselves in the event of any adverse events.

That argument seems fair. However, as always in ethics there are more issues to consider. The patient has probably already made sacrifices getting to the dentist and will be reluctant to return home untreated. In addition, if they are in pain, they are considered vulnerable subjects, and would be signing out of desperation.

Others may not fully understand the information nor comprehend the possible implications. While disclosure of information is one of the key elements of consent, there is also the requirements of competence to understand and voluntariness which these patients may not have.

Could the dentist consider carrying out non-sterile procedures with antibiotic cover "just in case"? The appropriate medication may or may not be available and such practices lead to the problems of overprescribing, and antibiotic resistance.

A worse scenario would be if the patient developed and allergic reaction to the medication after the clinician had left. This could have potentially fatal consequences. Who would then be held accountable? 
Furthermore antibiotics are often given for bacterial infections, but salivary transmittable viral infections are often overlooked.

Justice refers to fairness and includes consideration of legal, distributive and rights-based justice. Legal issues are complex and generally arise when some form of harm or damage has been inflicted on a patient. However an ethico-legal question is whether a dentist who has the expertise and ability to treat patients can justify turning them away?

In South Africa, a more pertinent discussion revolves around distributive justice. In the public health sector resources are limited and the dentist has to decide on how to distribute these fairly. If all patients are considered equal, how can one determine who is most deserving, in the most pain, or in greatest need. ${ }^{6}$

Rights-based justice may be based on the Batho Pele Principles. In terms of treatment, the principle of Access may be applied. This states that: All citizens have the right to equal access to the services to which they are entitled. This especially applies to disabled people, illiterate people and rural people who may have difficulty accessing government services.

Public servants have a special role to play, to make sure that those who need extra assistance get it. ${ }^{7}$ The ethical, compassionate dentist is often torn between their desire to adhere to these principles, and the harsh reality of not being able to comply due to local economic situation. It's no wonder then that dentistry is considered a stressful occupation!

"Best practice" principles to follow for reprocessing medical equipment and instruments

In the above scenario, if the dentist does treat patients while being fully aware that conditions are compromised, can this not then set a precedent for them to allow latitude in other areas of the practice? How many clinicians can honestly say they have not worked with the same bur on two different patients, re-used single-use items, not washed their hands between gloving, or carried out other "minor" transgressions in sterility?

The trouble is that once a door is opened for small lapses, it becomes all the more easy for others to slip through thereafter, which can potentially compromise the health and safety of their patients and staff.

This paper will not go into detail on the chain of duties, procedures, responsibilities and checklists that should be part of the standard disinfection protocol. However, clinicians need to be cognizant that sterilization and disinfection strategies are constantly changing, and they need to stay current and adjust their regimes accordingly.

Recent guidelines have been added for the inactivation of emerging pathogens, bioterrorist agents, and newly discovered blood-borne pathogens. In addition, other protocols have been altered to address toxicology, environmental and occupational concerns due to exposure to the chemicals. ${ }^{8}$

\section{CONCLUSION}

In all endeavors a chain is only as strong as the weakest link. It is futile for a clinician to be fully committed and adherent to evidence based practice in certain areas, but then allow for lapses in others.

Professionalism entails striving to always maintain the highest performance standards for all patients regardless of the circumstances. This is not always practically possible and that is where their integrity and moral values come into play.

We hope that this paper will stimulate a level of introspection as well as some convivial debates between colleagues around controversial issues in dentistry. We once again welcome feedback, comments and advice for others to follow.

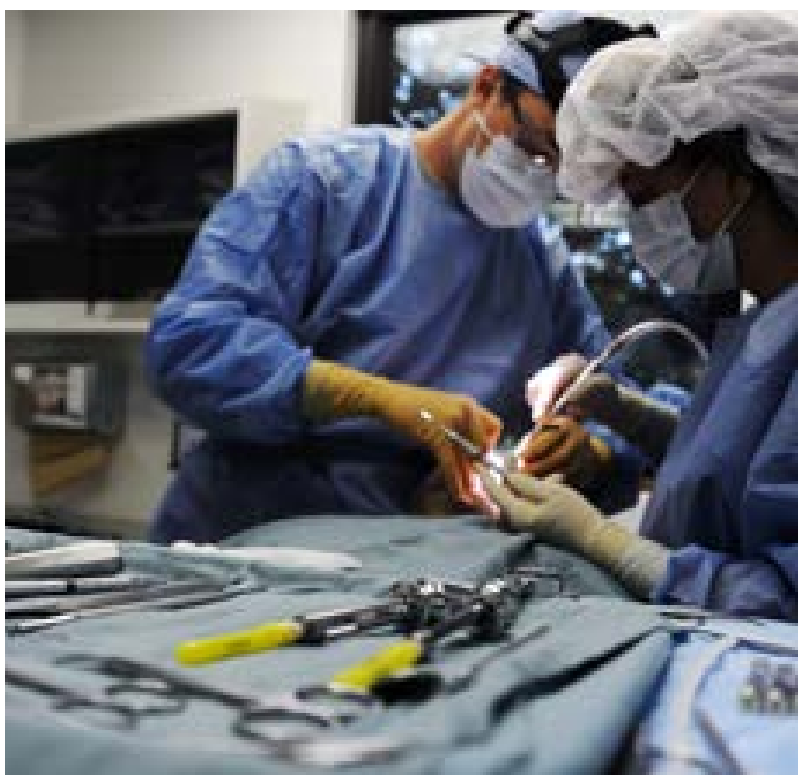

Image source: by Senior Airman Brittany Y. Bateman (U.S. Air Force photo).

\section{References}

1. Spaulding E. The role of chemical disinfection in prevention of nosocomial infections. Proceedings of the International Conference on Nosocomial infections, 1970. Chicago, IL: 247-54.

2. Favero MS. Strategies for disinfection and sterilization of endoscopes: The gap between basic principles and actual practice. Inf Control and Hosp Epidemiol. 1991: 12: 279-81.

3. Rutala WA, Clontz EP, Weber DJ, Hoffmann KK. Disinfection practices for endoscopes and other semicritical items. Inf Control Hosp Epidemiology. 1991; 12: 282 - 8

4. Centers for Disease Control and Prevention. A rational approach to disinfection and sterilization. (2008). Accessed at : https://www.cdc.gov/infectioncontrol/guidelines/disinfection/ rational-approach.html. Accessed on: 03-12-2019.

5. Beauchamp TL, Childress JF. Principles of biomedical ethics. New York: Oxford University Press.

6. Moodley K, Naidoo S. Ethics and the Dental Team. Van Schaik publishers, Pretoria. 2010; Chapter 3: 38-43.

7. Batho Pele. Improving Government Services. Accessed at: https://www.etu.org.za/toolbox/docs/govern/bathopele.html. Accessed on 5-12-2019.

8. Ling ML, Ching P, Widitaputra A, et al. APSIC guidelines for disinfection and sterilization of instruments in health care. Antimicrobial resist Infect Control. 2018; 7: 25. 